\title{
PARTNERSHIPS FOR URBAN REGENERATION: WHO NEEDS ACADEMIC RESEARCH?
}

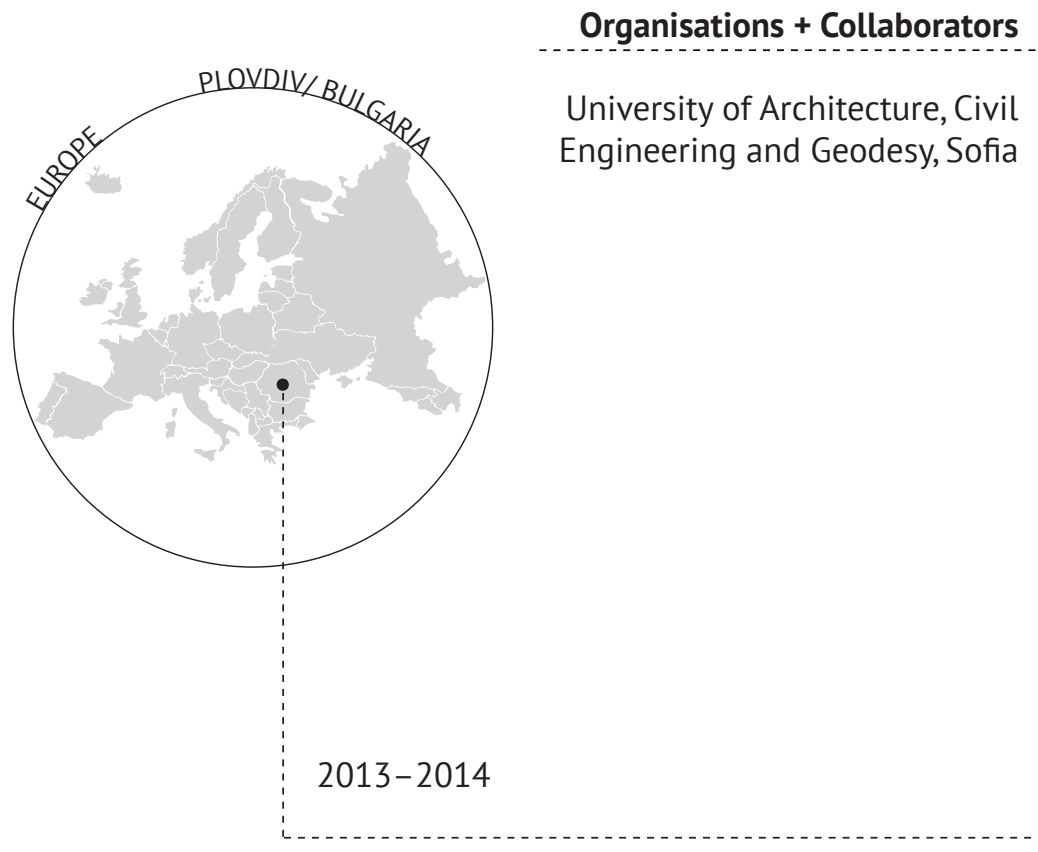

Authors

Elena Dimitrova

Architecture + urban

planning

\section{Introduction}

Approaching the city as an undertaking in which energy, resources, and social and cultural practices have been invested in providing the conditions for just and sustainable human development brings forth a request to empower people to take charge of their lives there. Such an approach poses challenges to the urban planning profession and requires urban experts with complex socio-technical knowledge. It also requests that urban experts not only cross disciplinary boundaries but also enter a transdisciplinary dialogue with local communities about their needs and values in building a path to the future. The growing awareness about the role of culture in that process has been clearly outlined in numerous political documents on sustainable urban development adopted at the global and European Union level at the beginning of the 21st century (European Commission, 2018; United Nations Educational, Scientific and Cultural Organization, 2013, 2016; United Cities and Local Governments, 2010). There, culture is referred to as a broad frame of urban communities' selfidentification through values, memories, attitudes and behaviour modes. European Union-supported 
initiatives like the European Capital of Culture (ECoC) and the European Year of Cultural Heritage (EYCH) have broadly supported the practical implementation of the concept. A closer study of the practical implementation of the initiatives on-site could help in better understanding the emerging practical challenges to transdisciplinarity in such complex urban processes involving the efforts, capacity and expectations of multiple actors.

A culture-based initiative in 2014 addressed urban regeneration challenges in the Bulgarian city of Plovdiv. ${ }^{1}$ It involved diverse academic, administrative, business and non-governmental organisation actors. The author's personal involvement in the initiative as the leader of an academic team of teachers and $\mathrm{PhD}$ and postgraduate students from the urban planning field was an opportunity to face real-life challenges to inter- and transdisciplinarity in the process. The discussion on challenges and lessons learned by the urban planners' academic team concerns the motivation and capacity of a Bulgarian university to join in real-life urban initiatives where the academic effort for a transdisciplinary dialogue on urban regeneration has to face short- and longer-term local policy considerations, business interests and citizens' concerns. Building a clear vision about the actors' diverse motivations for entering a partnership, communicating expectations about project results and agreeing in advance on each partner's role and responsibilities appeared to be among the major enablers on the path to effective transdisciplinary research partnership.

\section{The Kapana Quarter Project in Context}

The urban structure of Plovdiv maintains the material traces of millennia-long history. The Kapana quarter $^{2}$ is centrally located in the city at walking distance from the architectural reserve of the historic town. After developing in the late 19th century as a place of handicrafts and small businesses, the quarter underwent numerous transformations, while keeping its peculiar morphology - the curved narrow streets that outsiders often experience as a "trap," the small-scale buildings and the public places that are irregular in plan. For all these features, the Kapana quarter was officially declared an architectural reserve in the mid-1970s. Being close to, yet outside the traditional tourist paths in the city centre, the quarter kept its spirit and comfortably sheltered small business activities but also locally famous pubs and cafes. Despite an ongoing general decline, Kapana's vitality is still highly valued by local citizens, authorities and experts. Various initiatives have been undertaken in the quarter during the last two decades, ${ }^{3}$ drawing the attention of different actors to the quarter's development potential.

The Kapana Possible 2014 project was one of the numerous projects commissioned by Plovdiv municipality in support of Plovdiv's application to the European Capital of Culture 2019 programme. ${ }^{4}$ The application was in line with the municipality's strategy $y^{5}$ to build its present-day success upon its abundant cultural heritage and the joint creativity of numerous actors. Being a European capital of culture is nowadays considered not only a prestigious title but also one that opens up opportunities for culture-based urban development and urban regeneration (Stanganelli, 2019; Patel, 2013; Garcia \& Cox, 2013; Rampton, McDonald \& Mozuraityte, 2011; Palmer/Rae Associates, 2004).

The idea to invite four teams of students and teachers to join in the Kapana Possible 2014 project came from the One Foundation, ${ }^{6}$ a private organisation with a long track record of successful artistic and publishing initiatives in the field of architecture and culture. The one-year-long academic research project was intended as part of the larger long-term urban regeneration project undertaken by the municipality in 2013 to transform the historic quarter into an "area of creative industries."

The invitation to join in the regeneration project in the Kapana quarter was gladly accepted by 
the teachers from the programme in Urbanism at the University of Architecture, Civil Engineering and Geodesy (UACEG), as it was considered a good opportunity for closer communication with real-life urban practice by joining an innovative creative effort. The programme in Urbanism at the University of Architecture, Civil Engineering and Geodesy had been established in 2002, responding to the need for new planning experts in the country; it was also motivated by the growing interest of urban studies, globally and at the European Union level, in the sustainable development (SD) concept (Campbell, 1996; Næss, 2001), and the ongoing theoretical and policy debate within the planning community on the necessary rethinking of modernist planning and introduction of strategic and participatory planning approaches (Healey, 1997; Fincher \& Iveson, 2008). The programme had therefore been explicitly sensitive since its very beginning to the importance of contextual knowledge and to opportunities for urban research and collaboration with local urban practice (Dimitrova, 2014).

\section{The Academic Research Project: Process, Actors and Interactions}

In mid-2013, the One Foundation invited university teachers from four departments in three Bulgarian universities ${ }^{7}$ to organise their student teams and join in a small multidisciplinary research project on the Kapana quarter in Plovdiv. The project results were to be presented in the autumn of 2014 at the annual One Architecture Week international festival in Plovdiv as support for the city's application to the European Capital of Culture programme. The project was to be based on the creative district concept, recognised worldwide as a successful approach to regenerating urban areas in decay (Florida, 2005; Amsterdam Institute for Social Science Research, 2010) and already adopted by the municipality.

\section{Establishing the Partnership}

As the deadline for submitting the European Capital of Culture application was fast approaching and the activities schedule was tight, the partnership was officially established in November 2013. The contracts signed ${ }^{8}$ with the three invited faculties in early 2014 envisaged a one-year research process to be integrated within the ongoing teaching programmes. The official aim of the partnership within the Kapana Possible 2014 project was to apply a complex approach to an existing historic urban structure with significant architectural, social and cultural potential to develop a creative district close to the city centre. The four academic teams were expected to analyse the spatial and cultural identity and the development potential of the quarter from their specific professional points of view ethnology, sociology, urban planning and architecture. No explicit interdisciplinary interaction was envisaged due to the estimated shortage of time, yet the importance of a transdisciplinary approach was acknowledged and on-site meetings with diverse local actors - the municipal administration, non-governmental organisations, small businesses - were planned.

Regrettably, it was by that time too late to apply for funding within the research plan of the University of Architecture, Civil Engineering and Geodesy, and the One Foundation could provide no funding for the research activities, except to partially cover the teams' accommodation expenses during the planned field trip and the autumn festival. Yet, the benefits for all the "signing partners" were jointly acknowledged in advance: the project was expected to enrich the working experience of the academic teams - teachers as well as students - and the One Foundation in a real-life situation. The project was also seen as a potential basis for developing further joint projects together, thus providing for the continuity of the transdisciplinary partnership with the municipality of Plovdiv. 


\section{General Methodology Framework of the Project}

The four academic teams agreed upon a common methodology and a coordinated work schedule that comprised three main stages: desk research, field investigations including visual study, and meetings with local actors. The project proposals were to be presented at a festival in the quarter planned for October 2014. The project activities were supposed to be integrated into the ongoing educational process of the faculties in accordance with the teachers' estimation of the topic's relevance to the teaching modules. Due to the peculiarities of their disciplinary fields and the specific opportunities provided by the curricula, the teams chose to focus their analyses on different aspects of the urban process and to develop different types of intervention proposals. The urban planners proposed to put their emphasis on developing a strategic concept framework and operational guidelines for transforming the quarter. A joint mid-term reporting on the analysis results and the initial intervention proposals of the teams was planned for the spring of 2014 in order to enhance students' understanding about the peculiarities of different disciplinary approaches. This was considered an effective educational step to introduce the idea of interdisciplinary dialogue among future experts. Some collaboration with the graphic designers involved in the preparation of the festival was also proposed by the One Foundation and gladly accepted by all the teams, as it was expected to enhance students' competence in presenting their project results to the general public.

\section{The Urban Planning Team: Actors and Actions Undertaken}

After considering the potential opportunities provided by the summer semester curricula, the leading teachers of the planning team decided to organise the project activities outside the taught modules in order to enable greater flexibility and integrity of the research process. An open invitation was launched to all students from the programme in Urbanism, and the PhD students and graduates of the Urban Planning Department with specific experience and interests in the topic. A team of three teachers and ten students ${ }^{9}$ was thus constituted and started work.

\section{Conceptual Framework and Desk Research on Creative Industries}

At the first team meeting, it was claimed to be important that a broader framework should be set and development scenarios other than the "creative district" should be also considered; yet, due to the time restrictions, this was impossible to undertake. The conceptual framework of the urban project was thus built upon the scenario already chosen; it linked three emphases - creative industries, urban life in the quarter and creative neighbourhood networks. The desk research, undertaken next, outlined creative industries as a global phenomenon stimulating cities' competitiveness and identified successful practices worldwide. Applying a "bottom-up" approach, building vital multi-functional networks, and outlining the cultural and spatial identity of the urban environment were perceived as crucial for the efficient functioning of a creative industries area. The team analysed in parallel the historic transformations and the current morphology and functions of the Kapana quarter. The "hard" urban development factors included the material aspects of the urban process - the technical as well as the social infrastructure, location and accessibility of the quarter. The major "soft" factors considered were safety, cultural and social identity, diversity, tolerance, etc. The existing public places were estimated as key supportive elements in building and maintaining the creative neighbourhoods' networks. 


\section{The Field Study in Plovdiv and the Mid-Term Internal Reporting}

A two-day visit to Plovdiv jointly undertaken in April 2014 by all three student teams from Sofia enabled a brief on-site study in order to map the existing physical structure and the urban functions and flows and to build the visual image of the place. It was an opportunity to experience the rhythm of real life; the student team from Plovdiv provided some guidance, as they had been naturally able to spend a lot more time on-site. The visit was also combined with meeting some key local actors: municipal planning experts, a specialist from the city library, and representatives of citizens' organisations and small local businesses (arts and crafts). This provided a chance to ask questions about the past and present of the quarter, and to listen to various visions about creative industries in general and the envisaged future of the area.

A half-day joint seminar was hosted by the University of Architecture, Civil Engineering and Geodesy in Sofia in May 2014 for the teams to present their analysis results and discuss possible linking of the project proposals. A range of topics had been interpreted through different disciplinary approaches: ethnology, urban sociology, architecture and urban planning. Students as well as teachers were able to weigh the variety of issues addressed and ideas generated by the different teams. The opportunities stemming from linking them together were briefly discussed, yet were not practically used further, as each of the teams had to finalise their own project proposal by the end of May, which was also the end of the summer semester.

\section{The Urban Project: Process, Results and Messages}

The planners' team tried to comprehensively analyse the past and present of the Kapana quarter: its role in the historic development of the city and the ideas reflected in the urban plans adopted one after the other over the years. Comprehensive analysis of the physical structure was followed by estimations of its accessibility, morphology and everyday functioning (Figure II.7.2 and Figure II.7.3). Alternative development scenarios were compared with the one in the active city plans. Possible urban interventions to shelter creative industries in the quarter and provide for their mutual enrichment were considered. The team agreed that any change should be respectful of the genius loci of the quarter and specific rules of action and interaction there were needed.

The theoretical framework developed to guide the planners' work during the second stage of the project outlined two processes to take into consideration: (a) fragmentation; and (b) integration of the social and physical environment. These were then related to two development modes: from "inside-out," through bottom-up action initiated within the quarter and the city; and from "outside-in," through external interventions - investment, administrative restrictions on initiatives, competing interests, etc. The development factors identified concerned the importance of the quarter for the city, the presence of creative industries there, the changes in behaviour modes and living comfort of the inhabitants, the ongoing governance and self-governance practices, the traffic and parking pressure, and the visual impacts of the interventions in the urban environment.

By the end of the summer semester, the urban planning project had been generally structured, and a first draft of the proposals had been developed. However, the planning students already had to focus on finalising other educational projects and preparing for their exams; the enthusiasm to finalise the Kapana project was, in addition, negatively impacted by the single meeting with the graphic designer, who perceived the maps and schemes developed and the professional language used by the students as rather boring and difficult for a non-professional to understand. The coordinators were themselves already running out of time and eager to keep to their own schedule, so already in 


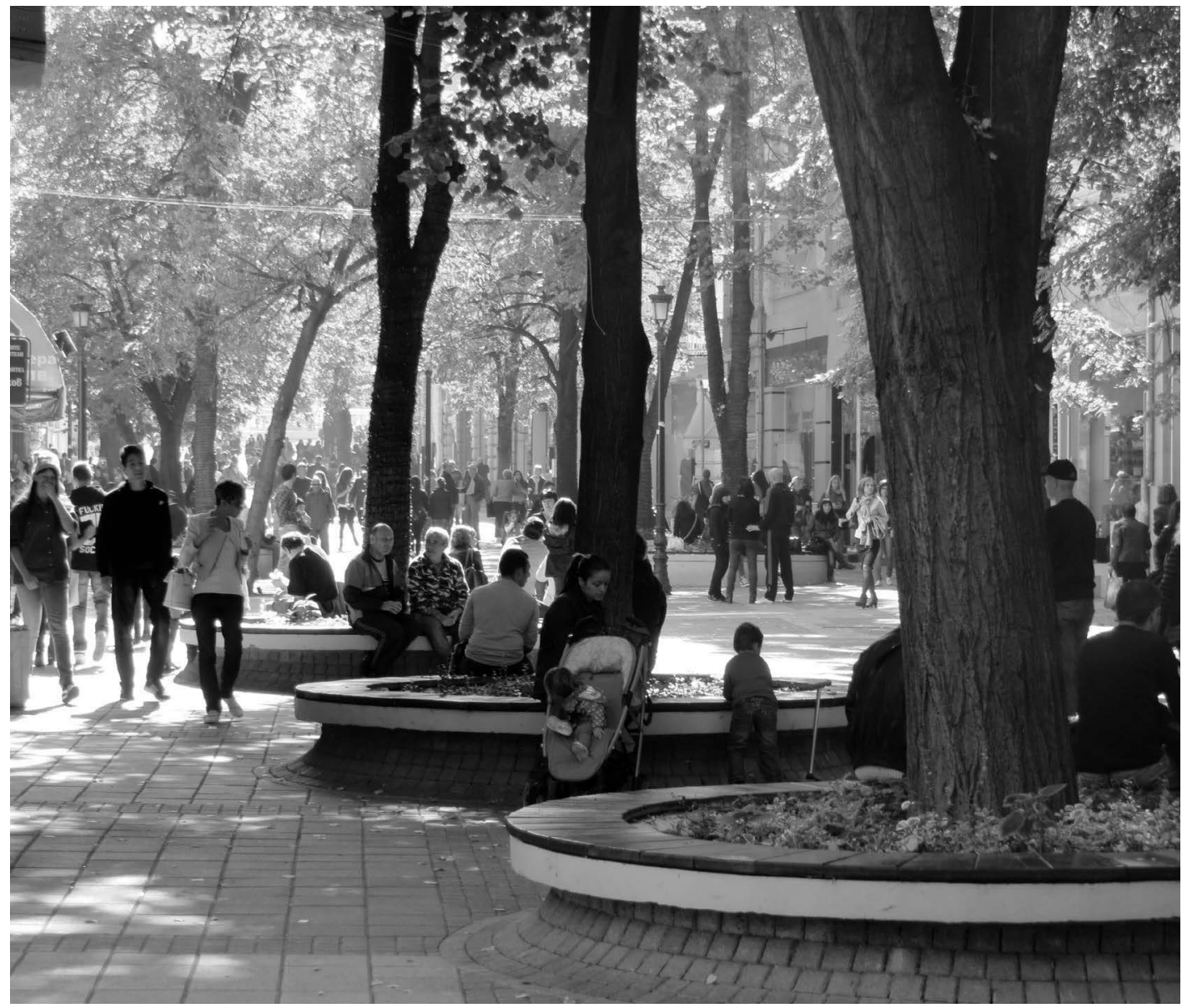

FIGURE II.7.2 A pedestrian street bordering Kapana quarter, 2014. Photo by Elena Dimitrova.

early summer they preferred to contact students from the planning team directly in order to obtain the graphic materials needed for the exhibition. Some of the students were also individually invited to join in the preparation of the supporting initiatives for the festival; the collaborative work on the project gradually slowed down, while individual efforts responded to the coming urgent requests.

The planned autumn exhibition in the Kapana quarter was ready on time; the academic results were displayed in the designated public places and on the exhibition premises; an urban game for the visitors to the event was organised by the students; and souvenirs (also with some stylised elements from the students' urban project) were available for purchase in the small shops opened in the quarter. Lectures by famous foreign artists and architects were included in the paid part of the festival programme (which was a bit too expensive for most of the students). In the meantime, the success of Plovdiv's application to the European Capital of Culture 2019 competition was officially announced and celebrated as a deserved happy ending of all the people's devoted efforts. 

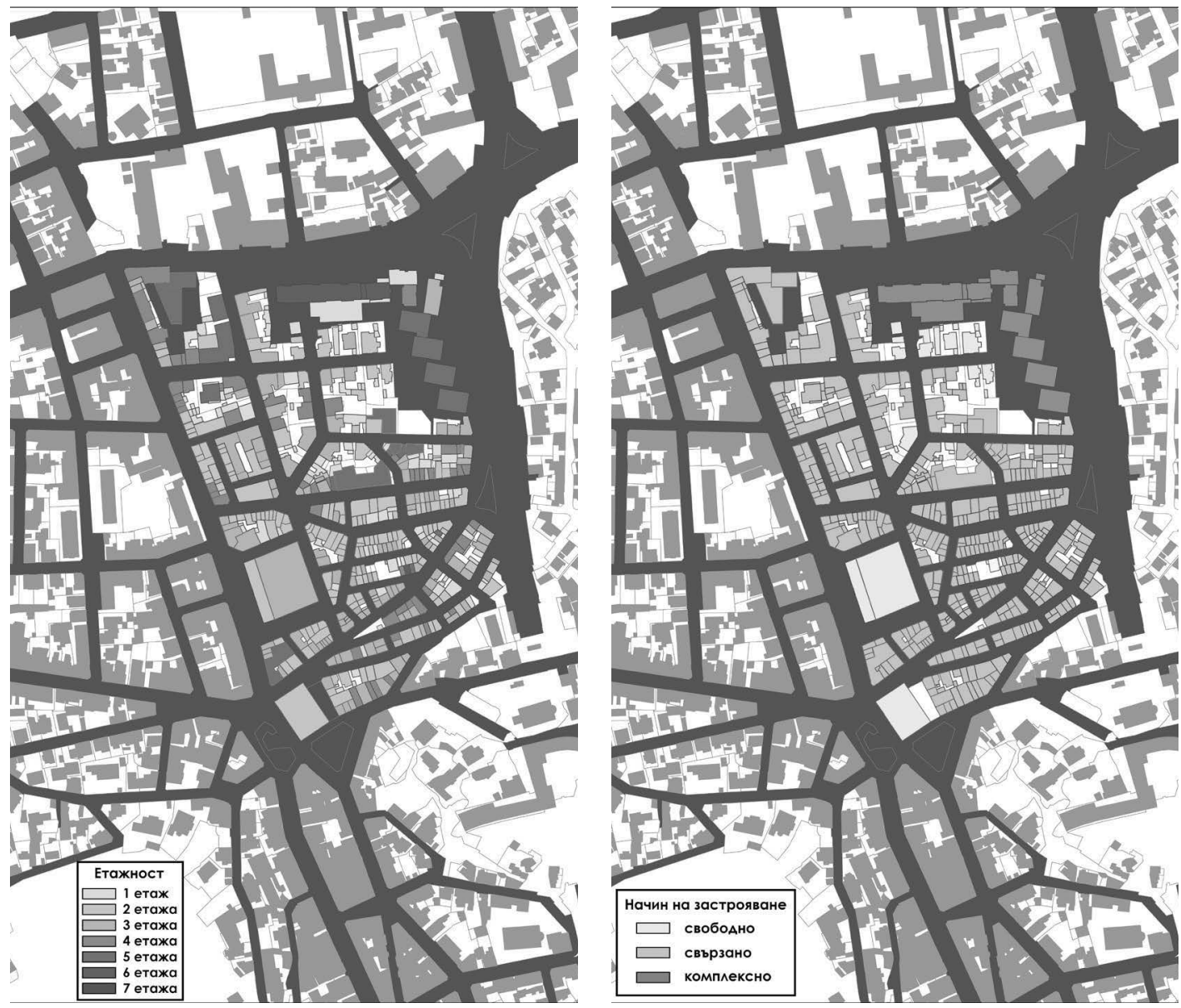

FIGURE II.7.3 Morphological and functional analyses of the area: (a) building heights, and (b) building types. Source: Hristina Kovacheva, urban planning team, UACEG.

\section{Post-Project Steps in the Academic Field}

The lack of time within a very tight schedule was the official reason why the results of the academic project were not further discussed with the local organising committee.

The conceptual valorisation of the research results and some self-reflection on the process were, however, important to the academic teams themselves. In October 2014, the Department of Sociology invited all the partner teams to a three-day seminar entitled "A meeting in Kapana" with a discussion question accompanying the invitation: "Why did we enter the Trap (Kapana)?" The planners' team brought their own questions to the seminar - on team working: "[Why] are we needed in the real-life urban process and how [should we] work together, how do we face challenges, what do we expect to achieve?"; on interdisciplinary dialogue: "How do we speak and what do we hear, how do we change through dialogue?"; on the urban process: "How do we identify a process in the city, how far could we influence it by planning the physical environment, [and] how can we be critical while keeping our hearts open to the urban process?"; on urban planning concepts in general: "What should we keep and 
what could we demolish in the city; who takes the responsibility for a decision; who knows how to intervene; who estimates the results of the intervention and how?"

Besides expressing a general satisfaction about being involved in an important large-scale urban event, the participants in the seminar tried to conceptualise the achievements, shortcomings and lessons learned through the project. Being in touch with real stakeholders and obtaining the opportunity to discuss their views and expectations about the future of the quarter was estimated as a major strength of the research process. Yet, the participants also shared their disappointment with the lack of clearly articulated feedback on the research results by the people to whom the research was addressed.

Although no effective steps were undertaken either by the local actors, the project coordinators or the academic teams for further contacts after the end of the initiative, the members of the planning team continued working on the Kapana case study in their next educational activities. There was a lot of information already accumulated and helpful contacts established on-site; there were challenges and knowledge gaps identified there that still needed analysis and interpretation. During the next winter semester, a course work with second-year students was started from previous findings and focused on changes needed in the technical infrastructure management of the area. The Kapana quarter was also used as a case study in the BSc diploma work on urban regeneration, developed by one of the active participants in the project (Karamitov, 2015), who outlined priority steps for turning Kapana into a creative district and developed a governance model for the quarter; he also recommended the establishment of a local decision-making body in the quarter including representatives of the city authorities, business actors, citizens' organisations and individual inhabitants. The diploma project identified major types of relevant businesses in the field of creative industries and their peculiar demands on urban locations and space. The establishment of co-working spaces sheltering creative work was considered explicitly supportive; a network of open public places promoting the development of the local community was proposed as a prerequisite for a resilient city. Another participant in the project is currently working on his $\mathrm{PhD}$ thesis analysing the historic dynamics of the morphology and skyline of the Kapana quarter as a case study.

\section{The Kapana Quarter: Life After the Project}

Periodic information in local and national media about the cultural calendar of Plovdiv indicates that a lot of tourist interest was attracted to the Kapana quarter, which has repeatedly staged successful cultural events and attracted visitors. This, logically, has brought life to the streets and attracted external customers to the local cafes and pubs. It also motivated investment interest and certain upgrades of the built environment (Figure II.7.4).

However, other images of the area - of closed shops on working days and empty streets - rather witness to growing social disparities and contrasts there (Figure II.7.5).

\section{Discussion: Inspirations, Disappointments and Lessons Learned}

The planning team's experience throughout the Kapana Possible 2014 project outlined important differences among the actors involved, regarding their motivations for undertaking the research effort, the methodological choices made, and the appreciation of the nature and benefits of the partnership. 


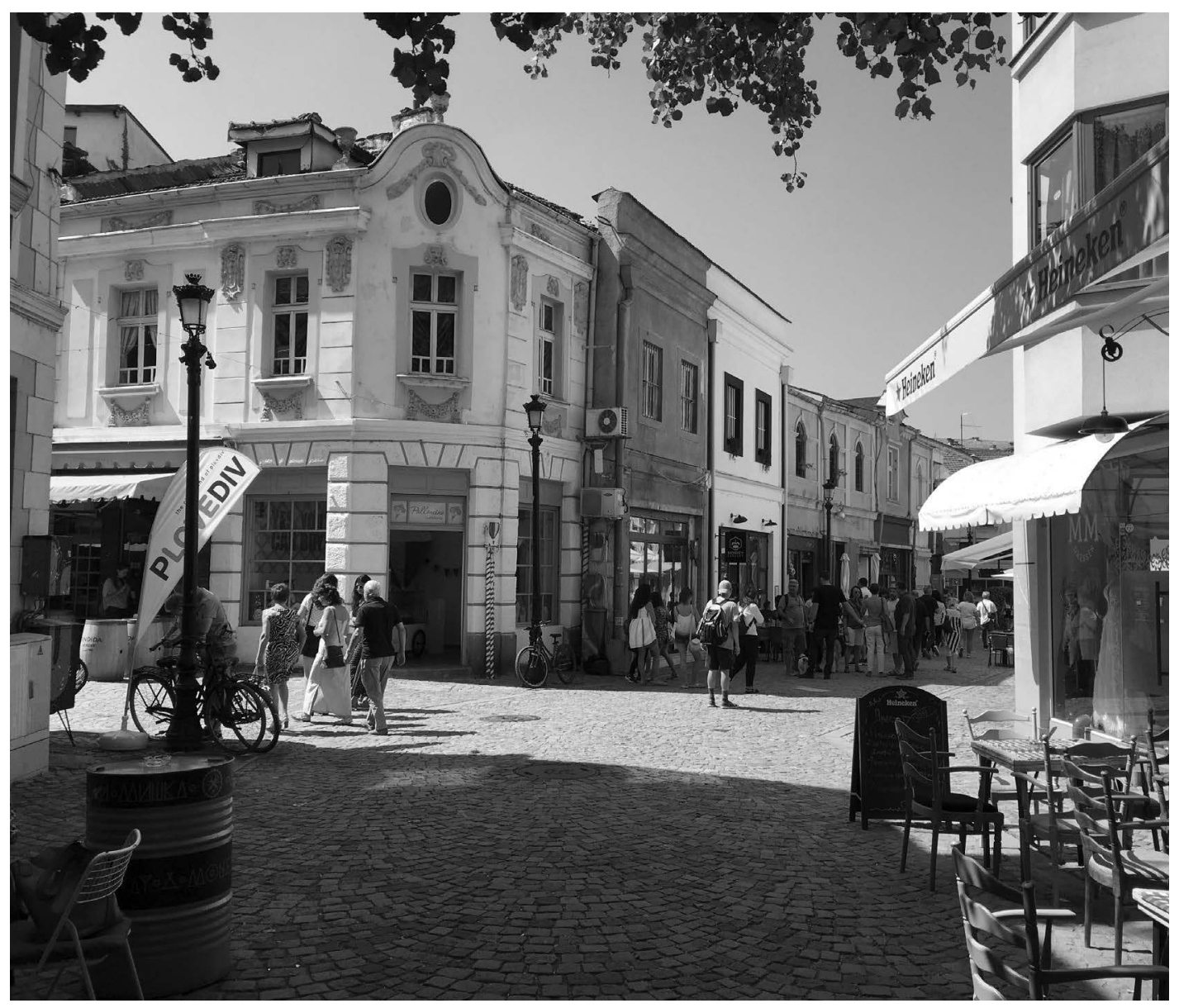

FIGURE II.7.4 The Kapana quarter, September 2019. Photo by Vladimir Petrov.

\section{Motivations for the Research Effort}

Although the invitation to the project was gladly accepted by the academic staff and the expected benefits were clearly formulated, the initiative was not planned by the university in advance and the additional time-consuming activities had somehow to be integrated within the established educational programme at very short notice. The planners' team tried to be as flexible as possible, yet with insufficient time for preparatory work it proved difficult to follow the methodological requirements of the academic research process. The lack of time and adequate funding also negatively influenced on-site research efforts and direct contacts with the other project partners.

\section{The Research Methodology}

Only a general methodological framework was initially agreed upon between the academic teams and the contractor. The flexibility of the methodological approach was the result of a pragmatic decision, which considered the diversity of the teaching programmes and the practical opportunities for action. Each university team felt free to develop their own topics in relevance to the emphases 


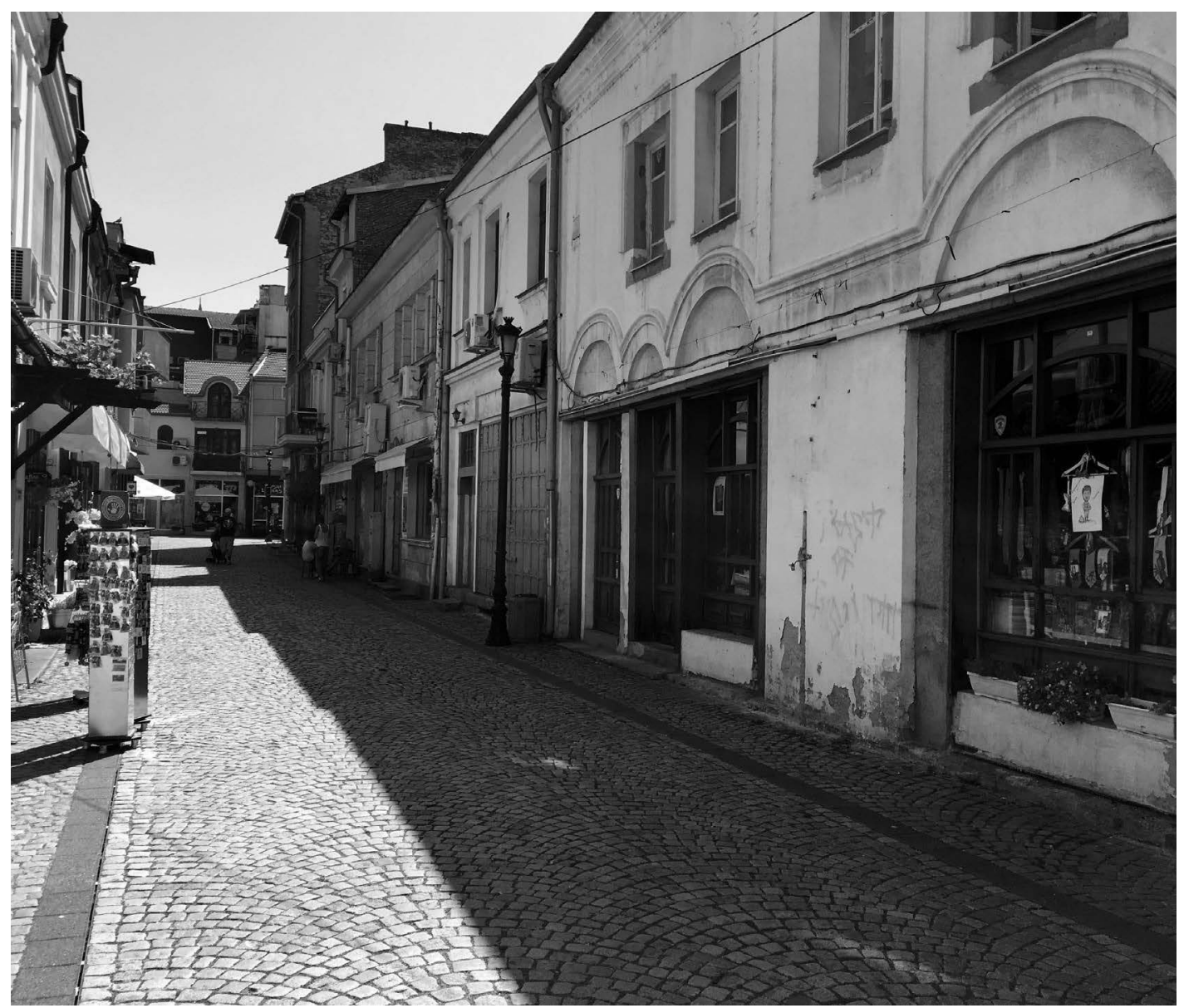

FIGURE II.7.5 The Kapana quarter, Plovdiv, September 2019: a working day morning. Photo by Vladimir Petrov.

considered important and meaningful. On the one hand, the chance for an expert appraisal of priorities could be considered a factor positively influencing the research process; on the other, there was no time for effective dialogue between the research teams, and opportunities for coordination were largely missed. Regrettably, the rather rigid administrative structures in the universities, the lack of funding and the insufficiency of time were all factors that acted as barriers to interdisciplinarity.

The terminology was never comprehensively discussed among the teams and with the coordinator. Many of the terms used had become broadly popular during the recent decades, some of them being often used as fashionable catchwords in urban initiatives worldwide: urban regeneration, creative industries, mixed use, etc. Therefore, their meaning was considered clear and beyond question; there was no attempt to clarify what exactly the terms would mean in the case of Kapana.

Uneven speeds within the process also became obvious in the different domains - academic, governance and business. It was difficult for the academic research to catch up with the established real-life timeframes. The practitioners had a straightforward pragmatic approach and the efficiency of efforts was explicitly targeted - it was important to use the research product at a particular point of 
the process in support of the political decision already taken and the city initiative under realisation. Thus the organisers of the event had to follow a tight schedule. Yet, the urban planners' team required theoretical debate and desk research as a starting point. Before focusing on the local context and developing the project proposal, they were interested in conceptualising the urban process itself. All meetings of the academic teams with the local administration were organised by the foundation in line with the project schedule and requirements; because of this, the opportunity to discuss the potential benefits of a continuous partnership with the municipality was largely missed. These were all shortcomings of a project-based effort with a limited timeframe.

There were also differences concerning the continuity of effort - the academic participants were eager to conceptualise the knowledge generated and to integrate it into their next educational and research efforts in the longer term; the coordinators were in a hurry to advance to another practical step. The academic team relied on desk research, debate and brainstorming; they considered important a dialogue-based field study, including interviews, and searched for opportunities to integrate relevant feedback into the next stages of the project. The coordinators required material results presented in a timely and attractive way to integrate them into a broader political effort, which was to be supported.

\section{The Partnership: Functional and Ethical Dimensions}

Functional as well as ethical aspects of the partnership should be considered important factors in the project development and outcome. The contracted research conditions and activities seemed fully acceptable at the outset of the project. Yet, the expectations of research collaboration and utilisation of results were not clearly communicated at the beginning; differences became increasingly visible later and caused disappointment on both sides. An initial major disappointment for the planning team was the fact that the political decision about the future function of the quarter as an area of creative industries had been already taken and the expected benefits of that option could not be questioned; the research results were only expected to confirm and illustrate them.

Different priorities could be also identified with respect to utilising the research results - while the academic participants considered the research and analysis parts very important, the contractors were mainly interested in the timely delivery of the project outcome and visual materials. After the city's application was announced as successful and the European Capital of Culture title was won, neither the project coordinators nor the local stakeholders were interested in discussing the academic teams' research results. These were surely discussed afterwards within the academic community, yet important aspects of the intervention impacts and the ways of interpreting them in terms of environmental justice remained largely neglected in practice. Neither the ongoing urban process in the quarter nor the consequences of the interventions undertaken received adequate monitoring and evaluation. The lack of access to relevant research programming and funding was a crucial factor for the organisation of the academic research activities. The academic teams were probably invited too late to join with their research effort in a process where political decisions had already been taken; students' work was rather considered an attractive addition to other activities in presenting the local authorities' concept to the public and to international bodies. The potential of universities to contribute to effective transdisciplinary research was underestimated from the very beginning. 


\section{Conclusion}

Despite largely being a missed opportunity for effective long-term transdisciplinary urban research, the Kapana project experience provided valuable insight into the motivations for action, the capacity for dialogue and the ethical choices made by different actors in the urban process in Bulgaria, which influence co-design, co-production and dissemination of urban knowledge.

The academic experience within the lifetime of the Kapana Possible 2014 project confirmed that transdisciplinary research is a time- and resource-consuming process. It is therefore important to communicate participants' views on the further valorisation of results well in advance. Building a common language is important to clarify actors' expectations of the research focus, time horizon, benefits, ownership and usage of the results. It is, however, the building of mutual trust and respect that enables the implementation of a common conceptual model, the exchange and dissemination of the knowledge generated. Contacts and dialogue are still required to convince local authorities that transdisciplinary approaches have the potential to bring far broader benefits in the long term than the ones currently aimed at. Involving students in a transdisciplinary process proved to be an important step because of their enthusiasm in discovering and interpreting real-life situations in a non-traditional way; it was also fruitful from an educational point of view by setting a focus on experts' sensitivity to a variety of stakeholders and interests, and on the capacity and tools needed for influencing a political process.

Four years after the project end and almost a year after Plovdiv met its first guests as a European Capital of Culture in 2019, there is a question still outstanding: What could have been different if local stakeholders had listened to the academic voices? Probably, by entering a real dialogue, it would have at least been possible for the academic planning team to learn more about keeping pace with political concerns and requirements. Hopefully, academic considerations about the sustainability of the regeneration activities envisaged - their long-term economic, social and cultural impacts - could have provided useful insights for decision-makers. At a deeper level, acknowledging the societal value of academic participation in transdisciplinary urban research would require a major change in existing urban culture in general - how the urban process is appreciated and respected by the different stakeholders and how the importance of effectively targeting the long-term impacts of urban planning and governance is valued. In countries like Bulgaria where the national planning system is undergoing a major change of devolution and democratisation, that would surely need a continuous - and honest - effort aimed at effective dialogue between urban education, research and practice.

\section{Acknowledgements}

The author is grateful to the One Foundation for the invitation to the project and the chance to test urban development concepts and ideas in a real-life urban context; to the students and teachers of the urban planning team for their devoted efforts and to the other three university teams for being our project partners; to the experts involved from Sofia and Plovdiv for their help in gathering the information needed and for their comments on the planning team's work and project results. The author remains fully responsible for any shortcomings of the present manuscript. 


\section{Notes}

1 Plovdiv is the second largest city in Bulgaria, an important administrative, industrial and cultural centre, with a population of 340,000 .

2 Kapana (Bulgarian for "trap") is a quarter in the city of Plovdiv, listed as a historic site of local importance in 1976 and later the object of several planned (yet never fully implemented) interventions in the late 20th century.

3 Successful projects of varying scales and foci have been realised in the quarter: The Zero project (authors: Kuzmanov \& Michev, http://openarts.info/proekt-0/) focused in 2010 on issues of symbolic images in the city and on the possibilities of building an integral image of the Kapana quarter. The Pavilion for the City project (Open Arts Foundation and Studio 81/2, http://openarts.info/besedka-za-grada-kapana/) organised a number of discussions on urban space in 2012, including the Kapana quarter. An initiative of local young architects and Cache Atelier, developed within the frame of the sixth edition of Sofia Architecture Week in 2013, located 75 cardboard cars in the streets of the quarter one early morning, before the cars of people working in the quarter were parked, thus raising public awareness about the way public space in the quarter was used (http://podtepeto.com/ailiak/zadrstikha-kapana-s-kartoneni-avtomobili/).

4 The European Capital of Culture (ECoC) initiative was proposed in 1985 as the European City of Culture by Greece's minister of culture Melina Mercouri, with the idea of raising Europeans' awareness about the common history and values within the richness and diversity of European cultures. A change in the European Capital of Culture programme rules in 2007 allowed broader access by Eastern European cities to the title.

5 After the political changes in the country in 1990, certain governance responsibilities were gradually transferred from the national to the local (municipal) level. Thus, active municipalities were already able to undertake strategic planning, to start implementing urban policies of their own and to compete for funding under European Union-funded national and European programmes.

6 The One Foundation for Culture and Arts was established in 2010 with the mission to provide for the continuous development of local culture by delivering rich, innovative and high-quality content that is accessible to all communities, and to enable cultural exchange between local and international artists.

7 Department of History and Theory of Architecture and Department of Urban Planning at the Faculty of Architecture, University of Architecture, Civil Engineering and Geodesy (UACEG), Sofia; Department of Sociology at the Faculty of Philosophy, Sofia University "St Kliment of Ohrid"; and Department of Ethnology at the Faculty of Philosophy and History, Plovdiv University "Paisii Hilendarski."

8 The academic teams were guaranteed access to all the information on the project development; they took on the obligation for coordinating their work and reporting intermediate results according to a schedule established by the main project coordinator in line with the municipality decision to develop the quarter as a "creative district."

9 The urban planning team: students from the MSc programme in Urbanism (alphabetically): Dimitar Andonov, Hristina Kovacheva, Kaloyan Karamitov, Vladimir Petrov, Yulia Dukova; teachers: Elena Dimitrova (team leader), Milena Tasheva-Petrova, Angel Burov; and consultants: Magdalena Kircheva and Nurhan Redzheb. 


\section{References}

Amsterdam Institute for Social Science Research (AISSR). (2010). Making creative-knowledge cities: A guide for policy makers. Published on behalf of the ACRE project, funded under Priority 7 'Citizens and Governance in a Knowledge-based Society' within the Sixth Framework Programme of the European Union (Contract No. 028270), University of Amsterdam. Retrieved on 30 October 2019 from http://acre. socsci.uva.nl/documents/Creative-KnowledgeCities-v3-lowres.pdf.

Campbell, S. (1996). Green cities, growing cities, just cities? Urban planning and the contradictions of sustainable development. Journal of the American Planning Association 62(3), 296-312.

Dimitrova, E. (2014). The "sustainable development" concept in urban planning education: Lessons learned on a Bulgarian path. Journal of Cleaner Production, 62, 120-127. http://dx.doi.org/10.1016/j. jclepro.2013.06.021.

European Commission (EC) (2018). A new European agenda for culture. Communication from the Commission to the European Parliament, the European Council, the Council, the European Economic and Social Committee and the Committee of the Regions. COM(2018)267 final, Brussels. Retrieved on 27 October 2019 from https://ec.europa.eu/culture/sites/culture/files/commission_communication_-_a_new_european_agenda_for_culture_2018.pdf.

European Union (EU) (2015). Getting cultural heritage to work for Europe. Report of the Horizon 2020 Expert Group on cultural heritage. DG for Research and Innovation. Retrieved 29 September 2018 from https:// publications.europa.eu/en/publication-detail/-/publication/b01a0d0a-2a4f-4de0-88f7-85bf2dc6e004.

Fincher, R. \& Iveson, K. (2008). Planning and diversity in the city: Redistribution, recognition, encounter. London: Palgrave Macmillan.

Florida, R. (2005). Cities and creative class. New York: Routledge.

Garcia, B. \& Cox, T. (2013). European capitals of culture: Success strategies and long-term effects. Study. Directorate General for Internal Policies, Policy Department B: structural and cohesion policies, culture and education. Retrieved 12 October 2018 from http://www.europarl.europa.eu/RegData/etudes/etudes/ join/2013/513985/IPOL-CULT_ET(2013)513985_EN.pdf.

Healey, P. (Ed.). (1997). Making strategic spatial plans. London: Routledge.

Karamitov, K. (2015). The "Kapana" ("Trap") of Plovdiv. Diploma thesis, MSc programme in Urbanism, public defence, Faculty of Architecture, University of Architecture, Civil Engineering and Geodesy (UACEG), Sofia.

Næss, P. (2001). Urban planning and sustainable development. European Planning Studies, 9(4), 503-524. doi:10.1080/713666490.

Palmer/Rae Associates (2004). European cities and capitals of culture. Part II. Study prepared for the European Commission. Retrieved 27 September 2018 from https:/ec.europa.eu/programmes/creative-europe/sites/ creative-europe/files/library/palmer-report-capitals-culture-1995-2004-ii_en.pdf.

Patel, K. (Ed.). (2013). The cultural politics of Europe: European capitals of culture and European Union since the 1980s. London: Routledge.

Rampton, J., McDonald, N., \& Mozuraityte, N. (2011). Interim evaluation of selection and monitoring procedures of European capitals of culture (ECoC) 2010-2016. Final report for the European Commission Directorate General for Education and Culture. Ecorys UK Ltd. Retrieved 2 October 2018 from https:// ec.europa.eu/programmes/creative-europe/sites/creative-europe/files/library/2011-capitals-culture-assignment-report_en.pdf.

Stanganelli, M. (2019). Cultural strategies for Urban regeneration: The effects of Policies Implemented by European Capitals of Culture. In Francesco Calabro, Lucia Della Spina, Carmelina Bevilacqua (Eds.) New Metropolitan perspectives. Local Knowledge and Innovation Dynamics towards Territory attractiveness Through the Implementation of Horizon/E2020/Agenda 2030 - Volume 2. Springer, Smart innovation, Systems and technologies 101, Cham, Switzerland; pp. 387-397.

United Cities and Local Governments (UCLG) (2010). Culture: Fourth Pillar of Sustainable Development. Policy Statement approved by the 3rd World Congress of UCLG on 17 November 2010 in Mexico. Retrieved 2 October 2018 from http://www.agenda21culture.net/sites/default/files/files/documents/en/zz_culture4pillarsd_en.pdf. 
United Nations Educational, Scientific and Cultural Organization (UNESCO) (2013). The Hangzhou declaration: Placing culture at the heart of sustainable development policies. Adopted in Hangzhou, People's Republic of China, on 17 May 2013. Retrieved 30 October 2019 from http://www.unesco.org/new/ fileadmin/MULTIMEDIA/HQ/CLT/images/FinalHangzhouDeclaration20130517.pdf.

United Nations Educational, Scientific and Cultural Organization (UNESCO) (2016). Culture: Urban Future. Global Report on Culture for Sustainable Cities, Paris. Retrieved 2 October 2018 from http://www. unesco.org/culture/culture-for-sustainable-urban-development/pdf-open/global-Report_en.pdf. 